\title{
Desenvolvimento local e processos participativos
}

DOI: http://dx.doi.org/10.20435/inter.v20i1.2444

Ao se referir ao conceito de desenvolvimento local há uma dificuldade de se unir consensos em razão da profusão de visões nos meios acadêmicos e intelectuais. O excesso de nomenclaturas tem criado controvérsias não só conceituais como também metodológicas.

O desenvolvimento das potencialidades de cada região é, segundo Neumann e Silveira (1999), o grande desafio do desenvolvimento local na busca da minimização da pobreza decorrente da globalização dos mercados e do aumento das diferenças sociais.

Amplia essa discussão Maluf (2000), para quem o tema desenvolvimento local, a partir de tentativas de avaliação ou mensuração voltadas ao desenvolvimento econômico, torna-se uma tarefa difícil.

Ainda que o contexto da década de 1970 tenha sido centralizador e autoritário, iniciou-se a discussão em torno da expressão Desenvolvimento local no Brasil, de diversas formas conceituais: desenvolvimento endógeno, desenvolvimento territorial, des4nvolvimento sustentável ou ainda desenvolvimento comunitário.

Coube ao desenvolvimento endógeno com enfoque social, a partir do protagonismo do indivíduo e do enfoque social visto, segundo Martin (1999), em sua comunidade, município ou região, como forma de quebrar as regras positivistas do desenvolvimento sob a ótica puramente econômica. Essa quebra de regras voltadas às iniciativas individuais ou coletivas de base econômica familiar é considerada como uma importante estratégia de desenvolvimento local, pois, além de maximização do aporte econômico, colabora de forma especial para uma maior interação social, para a construção de um tecido social local, municipal e regional.

Ao se voltar ao propósito de estimular as vocações regionais/locais/comunitárias, o desenvolvimento local propicia não só recursos humanos como potencializa o desabrochamento das competências, capacidades, habilidades de um determinado espaço territorial por meio da ativação colaborativa de agentes externos e internos, incrementando assim a cultura da solidariedade ao se tornar promotora de desenvolvimento no uso de suas potencialidades (ÁVILA, 2000).

O conceito de desenvolvimento local de base, ou seja, de "baixo para cima", é proposto por Santos e Rodriguez-Garavito (2006) como forma de vislumbrar, nas ações da sociedade civil, o ator principal do processo de construção coletiva, em razão de que a capacidade de decisão não pode nem deve ser entendida como exclusiva do Estado ou das elites econômicas locais.

Nesse contexto, os artigos do v. 20, n. 1 de 2019 que tratam sobre a palavra "Desenvolvimento", foram selecionados e apresentam diferentes enfoques.

Os artigos "Indicações Geográficas e desenvolvimento regional no Brasil: a atuação dos principais atores e suas metodologias de trabalho" e "O Indicador de Desenvolvimento Regional no Território do Tocantins" discutem a relação entre indicação geográfica e desenvolvimento regional dos principais atores tais quais: MAPA, SEBRAE, assim como o desenvolvimento regional de Tocantins.

Outro trabalho interessante é o artigo "O desenvolvimento conservador catarinense de 2007 a 2015", alicerçado no conceito de desenvolvimento para entender o processo ocorrido em Santa Catarina em mandatos governamentais distintos. Com um enfoque temático semelhante, o artigo "Índice bruto de sustentabilidade dos municípios de Mato Grosso do Sul" aponta que 
diversos municípios do estado apresentam resultados bem abaixo do ideal, em relação à estrutura político-administrativa e a ações voltadas à preservação do meio ambiente.

Tratar do desenvolvimento territorial a partir da revisão de literatura sobre os distritos industriais em experiências italianas é a temática do artigo "Análise do desenvolvimento territorial: a contribuição da experiência italiana". Discorrer sobre os processos de invisibilidade do "outro" nos discursos relacionados ao desenvolvimento é o que propõe o artigo intitulado "Discursos do desenvolvimento: (in)visibilidade do social, modernidade e progresso em Imperatriz, MA".

Ampliar a discussão sobre a relação entre o desenvolvimento socioeconômico e os indicadores de governança na América Latina, entre 2000 e 2014, é o que nos apresenta o artigo "Fatores condicionantes do desenvolvimento socioeconômico na América Latina: uma análise sob a perspectiva do PIB e dos indicadores globais de governança". Em outro viés, o artigo "Banco Palmas: inclusão e desenvolvimento local" apresenta as especificidades do Banco Comunitário Palmas a partir de sua moeda social como mecanismo de empoderamento social e geração de trabalho e renda.

Por fim, o artigo "Entre o desenvolvimento e a decolonialidade: Santarém, os portos e os conflitos" evidencia a existência de um pensamento hegemônico que implica desequilíbrio entre os que se beneficiam de um modelo economicista daqueles que permanecem marginalizados nas comunidades quilombola.

Profa. Dra. Arlinda Cantero Dorsa ${ }^{1}$

Editora Chefe da Interações

\section{REFERÊNCIAS}

ÁVILA, V. F.; CAMPOS, I. M. M; ROSA, M. W. C.; FERRO, R. F. F. C.; PAULITSCH, R. J. Formação educacional em desenvolvimento local: relato de estudo em grupo e análise de conceitos. Campo Grande: Editora UCDB, 2000.

MALUF, R. S. Atribuindo sentido(s) à noção de desenvolvimento. Estudos Sociedade e Agricultura, Rio de Janeiro, n. 15, p. 53-86, 2000.

MARTíN, J. C. Los retos por una sociedad a escala humana: El desarrollo local. In: SOUZA, M. A. Metrópole e globalização: conhecendo a cidade de São Paulo. São Paulo: CEDESP, 1999.

NEUMANN, P. S.; SILVEIRA, P. R. Enfoque sistêmico e desenvolvimento regional: a experiência da Universidade Federal de Santa Maria. In: BRANDBURGER, A.; TOMASINO, H. Seminário de sistemas de produção: conceitos, metodologias e aplicações. Curitiba: UFPR, 1999. p. 85-123. Disponível em: http:// www.ufsm.br/desenvolvimentorural/textos/livro.pdf. Acesso em: 10 ago. 2012.

SANTOS, B. de S.; RODRÍGUEZ-GARAVITO, C. A. Introduction: expanding the economic canon and searching for alternatives to neoliberal globalization. In: SANTOS, B. de S. (Org.). Another production is possible beyond the capitalist canon. London: Verso, 2006.

\footnotetext{
${ }^{1}$ Universidade Católica Dom Bosco (UCDB), Campo Grande, Mato Grosso do Sul, Brasil.
} 